Гигинейшвили Мария Теймуразовна

кандидат юридических наук, доцент кафедры международного права

Северо-Кавказского филиала Российского

государственного университета правосудия

\section{МЕЖДУНАРОДНЫЕ ПРЕДПИСАНИЯ О ПРОТИВОДЕЙСТВИИ ТОРГОВЛЕ ЛЮДЬМИ И ИХ ИМПЛЕМЕНТАЦИЯ В ЗАКОНОДАТЕЛЬСТВЕ РОССИЙСКОЙ ФЕДЕРАЦИИ}

\section{Аннотация:}

В статье рассматриваются международные договорные механизмы борьбы с торговлей людьми, а также порядок их имплементации в российское законодательство. Автор обращает внимание на эволюцию противодействия торговле людьми как на универсальном (под эгидой ООН), так и на региональных (Совет Европы, СНГ) уровнях. В работе разбирается предыдущая и действующая редакции сm. 127.1 УК РФ и проводится сравнительный анализ с положениями Палермского протокола. В итоге автор приходит к выводу о том, что, хотя уголовное законодательство в иелом криминализирует торговлю людьми и тем самым отвечает международным стандартам, Российская Федерация не в полном объеме имплементировала предписания Палермского протокола. В частности, отсутствует специальный закон о защите жертв торговли людьми, в котором были бы прописаны гарантии получения бесплатной помощи, защиты от уголовного преследования, депортации. Аналогичным образом не инкорпорированы соглашения и модельные законы о защите жертв и противодействии торговле людьми, принятые в рамках СНГ.

Ключевые слова:

имплементация, трансформация, Палермский протокол, торговля людьми, незаконный ввоз мигрантов, проституция, эксплуатация.
Gigineyshvili Maria Teymurazovna

PhD in Law, Associate Professor, International Law Department, North Caucasus branch of

Russian State University of Justice

INTERNATIONAL ANTI-HUMAN

TRAFFICKING REGULATIONS

AND THEIR IMPLEMENTATION

IN RUSSIAN LEGISLATION

The study discusses international treaty mechanisms to combat human trafficking and their implementation procedure in Russian legislation. The emphasis is placed on the evolution of counter-trafficking both at the universal (under the auspices of the UN) and regional (Council of Europe, CIS) levels. The author examines the previous and current wording of Article 127.1 of the Criminal Code of the Russian Federation and carries out a comparative analysis of the provisions of the Palermo Protocol. The author concludes that although criminal law generally criminalizes human trafficking and thereby meets international standards, the Russian Federation has not fully implemented the Palermo Protocol. In particular, there is no special law on the protection of human trafficking victims which provides guarantees to receive free assistance and be protected against criminal prosecution and deportation. Similarly, the CIS agreements, model laws on victim protection, and model anti-trafficking laws have not been incorporated by the Russian Federation.

Keywords: implementation, transformation, Palermo Protocol, human trafficking, migrant smuggling, prostitution, exploitation.

По словам Генерального секретаря ООН А. Гутерреша, «торговля людьми - это гнусное преступление, которое подпитывается нестабильностью, неравенством и конфликтами; торговцы людьми зарабатывают на человеческих надеждах и отчаянии; они охотятся на особо уязвимых лиц и крадут их фундаментальные права» [1]. Ежегодно сотни тысяч мужчин, женщин и детей становятся жертвами торговли людьми. Хотя невозможно указать достоверную цифру в силу высокой латентности данного преступления [2, с. 40], по данным Международной организации труда по состоянию на 2014 г., порядка 25 млн человек были жертвами рабского труда, а преступный доход от использования такой рабочей силы составляет 150 млрд долл. [3].

Мировое сообщество прошло долгий путь криминализации торговли людьми: от Международного соглашения 1904 г. и Международной конвенции 1910 г. о борьбе с торговлей белыми рабынями до Палермского протокола 2000 г. Примечательно, что Россия не только сейчас, но и в начале XX столетия, когда проблемы торговли людьми и соблюдения прав женщин не получали должного признания, одной из первых, наряду с Бельгией, Францией и Соединенным Королевством, ратифицировала упомянутые договоры [4]. Стоит отметить и вклад Лиги Наций, под эгидой которой были разработаны Международная конвенция о борьбе с торговлей женщинами и детьми 1921 г. и Международная конвенция о борьбе с торговлей совершеннолетними женщинами 1933 г. [5]. В дальнейшем эти документы были восприняты ООН при создании Конвенции 1949 г. о борьбе с торговлей людьми и эксплуатации проституции третьими лицами [6]. Проблема 
противодействия торговле людьми красной нитью проходит через Конвенцию МОТ о принудительном труде 1930 г., Конвенцию МОТ о наихудших формах детского труда 1999 г., Конвенцию МОТ об упразднении принудительного труда 1957 г., Конвенцию о правах ребенка и факультативные протоколы к ней, касающиеся торговли детьми, детской проституции, детской порнографрии и участия детей в вооруженных конфликтах [7].

Несмотря на внушительную правовую базу, универсальное определение торговли людьми (human trafficking) появилось только в декабре 2000 г., что было связано в первую очередь с отсутствием у государств единого понимания этого явления. Камнем преткновения служили вопросы незаконной миграции, добровольного ввоза незаконных мигрантов [8, р. 12]. Ситуация разрешилась принятием Протокола о предупреждении и пресечении торговли людьми, особенно женщинами и детьми, и наказании за нее, дополняющего Конвенцию ООН против транснациональной организованной преступности, иначе именуемого Палермским протоколом. Согласно ст. 3 указанного документа, торговля людьми - «осуществляемые в целях эксплуатации вербовка, перевозка, передача, укрывательство или получение людей путем угрозы силой или ее применением или других форм принуждения, похищения, мошенничества, обмана, злоупотребления властью или уязвимостью положения, либо путем подкупа, в виде платежей или выгод, для получения согласия лица, контролирующего другое лицо» [9]. При этом под эксплуатацией понимается как минимум эксплуатация проституции других лиц или иные формы сексуальной эксплуатации, принудительный труд или услуги, рабство или обычаи, сходные с рабством, подневольное состояние или извлечение органов [10]. Понятие «проституция» не раскрывается в Протоколе. Как известно из travaux préparatoires, Ad hoc, комитет по подготовке Конвенции 2000 г. и протоколов к ней пришел к выводу, что такой подход будет наиболее удачным, поскольку никоим образом не ограничит государства в части регламентации проституции в национальном законодательстве [11, р. 564], ведь существует ряд стран, легализующих ее.

Несколько лет спустя на региональном уровне в 2005 г. Советом Европы была принята Конвенция о противодействии торговле людьми, которая содержит тождественное содержащемуся в Палермском протоколе определение торговли людьми [12]. Однако Россия - единственная страна - участница Совета Европы, не подписавшая данную Конвенцию.

Продолжило общемировую тенденцию и СНГ, приняв 25 ноября 2005 г. Соглашение о сотрудничестве государств - участников СНГ в борьбе с торговлей людьми, органами и тканями человека, где понятие «торговля людьми» полностью совпадает с предложенным в Палермском протоколе вариантом [13]. В рамках СНГ были разработаны модельные законы «О противодействии торговле людьми» [14], «Об оказании помощи жертвам торговли людьми» [15], которые вводят категории детского секс-туризма, суррогатной матери, ревиктимизации, а также ряд других документов [16].

Россия ратифицировала Палермский протокол в 2004 г., предварительно дополнив УК РФ статьей 127.1 [17]. Однако определение торговли людьми в процессе имплементации претерпело трансформацию [18, с. 44]. Первоначальная редакция статьи выглядела следующим образом: «Торговля людьми, т. е. купля-продажа человека либо его вербовка, перевозка, передача, укрывательство или получение, совершенные в целях его эксплуатации...» [19].

Согласимся с И.С. Алихаджиевой и Т.Г. Дауровой, которые считают, что появление сочетания «купля-продажа» в определении торговли людьми - случай «неудачной трансформации» предписаний международного договора [20; 21, с. 92]. По мнению Г.В. Овчинниковой, такая заимствованная из международного договора дефиниция выпадает из системы УК РФ и устоявшегося понятийного аппарата [22, с. 17]. Е.Б. Мизулина утверждает, что при переводе с английского trafficking in human beings на русский не была передана точность содержания понятия и введение гражданско-правовой категории «купля-продажа» искажает состав преступления и лишь создает трудности квалификации [23]. Л.В. Иногамова-Хегай, в свою очередь, полагает, что законодатель специально при криминализации нового деяния использовал уже устоявшуюся терминологию (ранее существовала статья 152 УК РФ «Торговля несовершеннолетними») для целей облегчения усвоения содержания введенной статьи 127.1 УК РФ [24, с. 46]. В науке уголовного права высказывались позиции de lege ferenda переименовать статью 127.1 в «Торговля человеком» [25, с. 10], дополнить содержание категории «эксплуатация» (примечание 2 ст. 127.1 УК РФ) следующей формулировкой: «вовлечение несовершеннолетнего в совершение преступления или иных антиобщественных действий и использование лица в вооруженном конфликте» [26, с. 8].

Если международное определение торговли людьми состоит из трех элементов: действие (вербовка, перевозка...), средство (угроза применения силы, похищение...), цель (эксплуатация), то предложенная в УК РФ дефиниция была двучленной, она содержала ряд альтернативных действий (купля-продажа, вербовка, перевозка...), образующих объективную сторону преступления, и характеризовалась наличием такого признака субъективной стороны, как цель - эксплуатация. Причем при буквальном толковании текста статьи получалось, что купля-продажа должна была 
совершаться только в целях эксплуатации, что сужало сферу применения данной нормы. Новая редакция ст. 127.1 УК РФ устранила этот недостаток: «Купля-продажа человека, иные сделки в отношении человека, а равно совершенные в целях его эксплуатации вербовка, перевозка, передача, укрывательство или получение» [27]. Как указал Верховный суд РФ, «предлагаемая редакция рассматриваемой нормы, объективная сторона преступления которой - "купля-продажа человека" - не обусловлена обязательным признаком - "в целях эксплуатации", будет обеспечивать адекватную защиту от преступных посягательств против свободы, чести и достоинства личности» [28]. Важно отметить, что в отличие от Палермского протокола средства не указаны как обязательный признак объективной стороны торговли людьми. Таким образом, Российская Федерация приняла более широкий подход к пониманию этой категории. На наш взгляд, не только статья 127.1 УК РФ создает механизм противодействия торговли людьми. В уголовном законе имеются отчасти смежные составы: ст. 127.2 («Использование рабского труда»), ст. 241 («Организация занятия проституцией»), ст. 322 («Незаконное пересечение Государственной границы РФ»), ст. 322.1 («Организация незаконной миграции»). В силу конкуренции перечисленных норм, а также высокой латентности торговли людьми статистика уголовных дел, возбужденных по ст. 127.1 УК РФ, не соответствует действительности [29, с. 60].

Стоит отметить, что Палермский протокол, помимо требования криминализации, содержит ряд важных положений о реабилитации, оказании медицинской, психологической, материальной помощи, репатриации жертв и сотрудничестве государств. Однако эти предписания не имплементированы должным образом в законодательстве РФ. Как было отмечено Бюро Международной организации по миграции в РФ в 2008 г., в стране не существует комплексного законодательства против торговли людьми, которое разделяло бы сферу полномочий между компетентными органами, предполагало бы механизм контроля и меры по профрилактике [30]. На сегодняшний день особых изменений в данном направлении не произошло. До сих пор на национальном уровне не дано нормативное определение понятия «жертвы торговли людьми», не подготовлены специальные законы. В отличие от России Азербайджан [31], Белоруссия [32], Таджикистан [33], Узбекистан [34] приняли законы о противодействии торговле людьми и оказании помощи жертвам торговли людьми. В Казахстане утвержден Стандарт оказания специальных социальных услуг жертвам торговли людьми [35].

В России еще в 2003 г. был подготовлен проект федерального закона «О защите жертв торговли людьми», содержащий достаточно широкий перечень гарантий, предоставляемых потерпевшим. Однако при первом прочтении складывается впечатление, что он больше ориентирован на жертв торговли - граждан РФ. В нем детально описываются функции консульских учреждений РФ по оказанию помощи потерпевшим, находящимся за пределами нашего государства. Примечательно, что проект допускает выдачу вида на жительство иностранцам - жертвам торговли людьми в случае их помощи в поимке виновных. При этом, на наш взгляд, подобная гарантия носит очень ограниченный характер: в случае отказа от сотрудничества с правоохранительными органами лицо, незаконно оказавшееся на территории РФ, подлежит депортации [36].

Несмотря на имеющиеся недоработки в законодательстве о противодействии торговле людьми, отметим, что Российской Федерацией сделаны шаги в направлении выполнения возложенных на нее международных обязательств, помимо введения ст. 127.1 в УК РФ. В частности, принят Федеральный закон «О государственной защите потерпевших, свидетелей и иных участников уголовного судопроизводства», который стал базой для защиты прав жертв торговли людьми в ходе расследования и судебного разбирательства [37]. Указом президента РФ «О Стратегии национальной безопасности Российской Федерации» к числу основных угроз государственной и общественной безопасности отнесена, помимо прочего, и торговля людьми [38].

При подведении итогов стоит сказать, что попытки противодействовать торговле людьми были предприняты мировым сообществом еще в начале XX в. В настоящее время на универсальном и региональном уровнях разработан ряд международных договоров, ставящих в качестве основной или косвенной цели борьбу с этим общественно опасным явлением. Главным источником выступает Палермский протокол 2000 г. Россия, будучи его участником, криминализировала торговлю людьми, несколько трансформировав договорное определение: объективная сторона дополнена «куплей-продажей», опущены «средства» как обязательный признак. Тем не менее, не имплементировав положения о гарантиях жертв и сотрудничестве государств, РФ не в полном объеме выполнила взятые на себя международные обязательства.

\section{Ссылки:}

1. Human Trafficking 'Takes Many Forms, Knows No Borders', Secretary-General Says in Message for World Day [Электронный ресурc] : UN SG Message for the World Day // United Nations. 2018. July 24. URL: https://www.un.org/press/en/2018/sgsm19146.doc.htm (дата обращения: 30.08.2019). 
2. Rudolph A., Shneider F. International Human Trafficking: Measuring Clandestinity by the Structural Equation Approach // Social Inclusion. 2017. Vol. 5, iss. 2. P. 39-58. https://doi.org/10.17645/si.v5i2.909.

3. 40 Million in Modern Slavery and 152 Million in Child Labour around the World [Электронный ресурс] // International Labour Organization. 2017. Sept. 19. URL: https://www.ilo.org/global/about-the-ilo/newsroom/news/WCMS_574717/lang--en/index.htm (дата обращения: 30.08.2019).

4. International Agreement for the Suppression of the 'White Slave Traffic' [Электронный ресурс] : 1904. May 18 // United Nations Treaty Collection. URL: https://treaties.un.org/Pages/ViewDetails.aspx?src=TREATY\&mtdsg_no=VII-8\&chapter=7\&clang= en\#3 (дата обращения: 30.08.2019).

5. Международная конвенция о борьбе с торговлей женщинами и детьми [Электронный ресурс] : от 30 сент. 1921 г. // Pravo.levonevsky.org. URL: http://pravo.levonevsky.org/bazaby/mdogov/megd4973.htm (дата обращения: 30.08.2019) ; Международная конвенция о борьбе с торговлей совершеннолетними женщинами [Электронный ресурс] : от 11 окт. 1933 г. // Ibid. URL: http://pravo.levonevsky.org/bazaby/mdogov/megd4956.htm (дата обращения: 30.08.2019).

6. Конвенции о борьбе с торговлей людьми и эксплуатации проституции третьими лицами [Электронный ресурс] : принята резолюцией 317 (IV) Генеральной Ассамблеи от 2 дек. 1949 г. // OOH : официальный сайт. URL: https://www.un.org/ru/documents/decl_conv/conventions/trafficking_suppression.shtml (дата обращения: 30.08.2019).

7. Международные договоры в области борьбы с торговлей людьми [Электронный ресурс] // Управление Верховного комиссара $\mathrm{OOH}$ по правам человека : офрициальный сайт. URL: https://www.ohchr.org/Documents/lssues/Women/WRGS/OnePagers/IntInstrumentsconcerningTraffickingpersons ru.pdf (дата обращения: 30.08.2019).

8. Gallagher A.T. The International Law of Human Trafficking. Cambridge, 2010.596 p.

9. Протокол о предупреждении и пресечении торговли людьми, особенно женщинами и детьми, и наказании за нее, дополняющий Конвенцию Организации Объединенных Наций против транснациональной организованной преступности [Электронный ресурс] : принят резолюцией 55/25 Генеральной Ассамблеи от 15 нояб. 2000 г. // ООН : официальный сайт. URL: https://www.un.org/ru/documents/decl_conv/conventions/protocol1.shtml (дата обращения: 30.08.2019).

10. Ibid.

11. Scarpa S. Fighting Against Human Trafficking for Commercial Sexual Exploitation: The Actions in Western Europe // Revue International de Droit Penal. 2010. No. 3-4. P. 563-587.

12. Конвенция Совета Европы о противодействии торговле людьми [Электронный ресурс] : от 16 мая 2005 г. // Council of Europe. URL: https://rm.coe.int/16805a937а (дата обращения: 30.08.2019).

13. Соглашение о сотрудничестве государств - участников СНГ в борьбе с торговлей людьми, органами и тканями человека [Электронный ресурс] : от 25 нояб. 2005 г. // Законодательство стран CHГ : база данных. URL: http://base.spinform.ru/show doc.fwx?rgn=14410 (дата обращения: 30.08.2019).

14. О противодействии торговле людьми [Электронный ресурс] : модельный закон : от 3 апр. 2008 г. // Консорциум кодекс: электронный фонд правовой и нормативно-технической документации. URL: http://docs.cntd.ru/document/902124613 (дата обращения: 30.08.2019).

15. Об оказании помощи жертвам торговли людьми [Электронный ресурс] : модельный закон : от 3 апреля 2008 г. // Там же. URL: http://docs.cntd.ru/document/902124615 (дата обращения: 30.08.2019).

16. Кобец П.Н. Правовое регулирование сотрудничества правоохранительных органов государств - участников СНГ в борьбе с торговлей людьми // Инновационная наука. 2017. Т. 2, № 3. С. 122-123.

17. Уголовный кодекс РФ // Собрание законодательства РФ. 1996. № 25. Ст. 2954

18. Ищенко Г.К. К вопросу об уголовной ответственности за торговлю людьми и использование рабского труда // Юристъ-правововедъ. 2008. № 6 (31). С. 43-45.

19. Уголовный кодекс РФ.

20. Алихаджиева И.С. Недостатки законодательной регламентации уголовно-правовой борьбы с торговлей людьми // Уголовное право. 2006. № 5. С. 4-7.

21. Даурова Т.Г. Государство на защите конституционного права на свободу // Конституционные чтения : межвузовский сборник научных трудов. Саратов, 2005. Вып. 6. С. 88-94.

22. Гилинский Я.И., Овчинникова Г.В. Торговля людьми: криминологический и уголовно-правовой анализ : учебное пособие. СПб., 2008. 41 с

23. О состоянии борьбы с торговлей людьми в РФ : доклад / под ред. Е.Б. Мизулиной. М., 2006.

24. Иногамова-Хегай Л.В. Торговля людьми в российском и международном уголовном праве // Уголовно-правовые, пенитенциарные принципы и их реализация: правотворческий, правоприменительный уровни : материалы всероссийской научно-практической конференции / под ред. Б.Т. Разгильдиева. В 2 ч. Саратов, 2005. С. 46-48.

25. Гетман И.Б. Уголовная ответственность за торговлю людьми : автореф. дис. ... канд. юрид. наук. Тюмень, 2010. 25 с.

26. Жинкин А.А. Торговля людьми и использование рабского труда: Проблемы квалификации и соотношение со смежными составами преступлений : автореф. дис. ... канд. юрид. наук. Краснодар, 2006. 25 с.

27. Уголовный Кодекс РФ.

28. На проект федерального закона «О внесении изменений в статью 127.1 УК РФ» [Электронный ресурс] : официальный отзыв Верховного суда РФ от 5 апр. 2007 г. № 1071-2/общ. Доступ из справ.-правовй системы «Гарант».

29. Горбунов А.Н., Стукалов В.В. Проблемы борьбы с торговлей людьми и организацией проституцией // Вестник Краснодарского университета МВД России. 2012. № 4 (18). С. 59-62.

30. Предотвращение и противодействие распространению рабства и торговли людьми в РФ [Электронный ресурс] : Итоговый доклад по исследовательской части проекта Европейского союза, реализуемого Бюро Международной организации по миграции (МОМ) в РФ «Предотвращение торговли людьми в РФ» // Российский Красный Крест. 2018. URL: http://www.spbredcross.org/images/docs/Prevention-and-Counteraction-to-the-Spread-of-Slavery.pdf (дата обращения: 30.08.2019).

31. Закон Азербайджанской Республики о борьбе с торговлей людьми [Электронный ресурс] : 2005 г. // Министерство внутренних дел Азербайджанской Республики. URL: https://www.mia.gov.az/index.php?/ru/content/336 (дата обращения: 30.08.2019)

32. О противодействии торговле людьми [Электронный ресурс] : закон Республики Беларусь от 7 янв. 2012 г. // База нормативных правовых актов Республики Беларусь. URL: http://pravo.newsby.org/belarus/zakon0/z167.htm (дата обращения: 30.08.2019).

33. Раджабов Р.М. Оптимизация закона Республики Таджикистан «О противодействии торговле людьми и оказании помощи жертвам торговли людьми» // Труды Академии МВД Республики Таджикистан. 2017. № 3 (35). С. 55-62.

34. О противодействии торговли людьми : закон Республики Узбекистан // Собрание законодательства Республики Узбекистан. 2008. № 16. Ст. 118. 
35. Об утверждении стандарта оказания специальных социальных услуг жертвам торговли людьми [Электронный ресурс] : стандарт от 24 февр. 2016 г. // Государственные услуги и инфрормация онлайн. URL: http://egov.kz/cms/ru/law/list/V1600013543 (дата обращения: 30.08.2019).

36. О защите жертв торговли людьми [Электронный ресурс] : проект федерального закона от 30 окт. 2003 г. // Женщина и общество : информационный портал. URL: http://www.owl.ru/win/docum/rf/traffic-law.htm (дата обращения: 30.08.2019)

37. Усиление мер по противодействию торговли людьми в Санкт-Петербурге и Ленинградской области [Электронный ресурс] : рекомендации // Санкт-Петербургский центр международного сотрудничества Красного Креста. 2017. URL: http://www.spbredcross.org/images/recomendacii.pdf (дата обращения: 30.08.2019).

38. О Стратегии национальной безопасности РФ : указ президента РФ от 31 дек. 2015 г. № 683 // Собрание законодательства РФ. 2016. № 1, ч. ІІ. Ст. 212.

\section{References:}

'40 Million in Modern Slavery and 152 Million in Child Labour around the World' 2017, International Labour Organization, September 19, viewed 30 August 2019, <https://www.ilo.org/global/about-the-ilo/newsroom/news/WCMS 574717/lang--en/index.htm>.

Alikhadzhieva, IS 2006, 'Failures in the Legislative Regulation of the Criminal Law Fight Against Human Trafficking', Ugolovnoe pravo, no. 5, pp. 4-7, (in Russian).

Daurova, TG 2005, 'The State Defensing the Constitutional Right to Freedom', Constitutional Readings: Interuniversity Collection of Studies, Saratov, iss. 6, pp. 88-94, (in Russian).

Gallagher, AT 2010, The International Law of Human Trafficking, Cambridge, 596 p.

Getman, IB 2010, Criminal Liability for Human Trafficking, PhD thesis abstract, Tyumen, 25 p., (in Russian).

Gilinsky, Yal \& Ovchinnikova, GV 2008, Human Trafficking: Forensic and Criminal Legal Analysis: Manual, St. Petersburg, 41 p., (in Russian).

Gorbunov, AN \& Stukalov, VV 2012, 'Problems of the Fight Against Human Trafficking and Prostitution', Vestnik Krasnodarskogo universiteta MVD Rossii, no. 4 (18), pp. 59-62, (in Russian).

'Human Trafficking 'Takes Many Forms, Knows No Borders', Secretary-General Says in Message for World Day: UN SG

Message for the World Day' 2018, United Nations, July 24, viewed 30 August 2019 , <https://www.un.org/press/en/2018/sgsm19146.doc.htm>.

Inogamova-Khegai, LV 2005, 'Human Trafficking in Russian and International Criminal Law', in BT Razgildiev (ed.), Criminal

Law, Penitentiary Principles and Their Implementation: Law-Making, Law Enforcement Levels: Proceedings of All-Russian Research-to-Practice Conference, in 2 parts, Saratov, pp. 46-48, (in Russian).

'International Agreement for the Suppression of the 'White Slave Traffic', May 18, 1904' 2019, United Nations Treaty Collection,

viewed 30 August 2019, <https://treaties.un.org/Pages/ViewDetails.aspx?src=TREATY\&mtdsg_no=VII-8\&chapter=7\&clang=_en\#3>

Ischenko, GK 2008, 'On Criminal Liability for Human Trafficking and Slave Labour', Yurist"-pravovoved", no. 6 (31), pp. 43-45,

(in Russian)

Kobets, PN 2017, 'Legal Regulation of Cooperation among the CIS Law Enforcement Agencies When Countering Human Trafficking', Innovatsionnaya nauka, vol. 2, no. 3, pp. 122-123, (in Russian).

Mizulina, EB (ed.) 2006, Report on the Fight Against Human Trafficking in the Russian Federation, Moscow, (in Russian).

Radzhabov, RM 2017, 'Optimizing the Law of the Republic of Tajikistan on Countering Human Trafficking and Assisting

Human Trafficking Victims', Trudy Akademii MVD Respubliki Tadzhikistan, no. 3 (35), pp. 55-62, (in Russian).

Rudolph, A \& Shneider, F 2017, 'International Human Trafficking: Measuring Clandestinity by the Structural Equation Approach', Social Inclusion, vol. 5, iss. 2, pp. 39-58, https://doi.org/10.17645/si.v5i2.909.

Scarpa, S 2010, 'Fighting Against Human Trafficking for Commercial Sexual Exploitation: The Actions in Western Europe', Revue International de Droit Penal, no. 3-4, pp. 563-587.

Zhinkin, AA 2006, Human Trafficking and Slave Labour: Problems of Their Qualification and Correlation with Related Offenses, PhD thesis abstract Krasnodar, 25 p., (in Russian). 